\title{
Do campo à escola: reflexões sobre a arquitetônica dos discursos produzidos no contexto de transmissão de saberes tradicionais
}

\author{
Cristiane Dominiqui Vieira Burlamaqui \\ Universidade de São Paulo (USP), São Paulo, São Paulo, Brasil \\ crisburla@usp.br
}

DOI: http://dx.doi.org/10.21165/el.v46i3.1698

\begin{abstract}
Resumo
Apresentamos os resultados iniciais da etapa de descrição e análise dos gêneros do discurso emergentes no contexto da transmissão dos saberes de comunidades tradicionais da Amazônia paraense. Utilizamos, como pedra angular de nossas reflexões, a teoria dialógica do discurso. A reflexão, em torno do material linguístico, advindo dos registros, da análise e da descrição dos gêneros do discurso produzidos nas atividades enunciativas que emergem durante $o$ processo da transmissão oral de técnicas tradicionais usadas na apropriação dos recursos naturais - o etnoconhecimento e/ou a Etnociência (DIEGUES, 2008) - possibilita alimentar o debate sobre o problema da relação recíproca estabelecida entre a infraestrutura e a superestrutura, a materialidade discursiva e a vida vivida, e como a relação entre essas quatro instâncias revela fragmentos da vida cotidiana de populações tradicionais.
\end{abstract}

Palavras-chave: saberes tradicionais; teoria dialógica do discurso; signo ideológico.

From the countryside to the school: reflections about the architectural context of the discourses produced in the context of transmission of traditional knowledge

\begin{abstract}
We present the initial results of the description and analysis stage of emerging discourse genres in the context of the transmission of traditional knowledge about Pará Amazon's communities. We used as the cornerstone of our reflections, studies of the Bakhtin Circle. The reflection around the linguistic material arising from records, analysis and from the description of discourse genres produced in the enunciation activities that emerge during the oral transmission process of traditional techniques used in the appropriation of natural resources - the ethnoknowledge and/or ethnoscience (DIEGUES, 2008) - make it possible to feed the debate about the problem of the reciprocal relationship established between infrastructure and superstructure, the discursive materiality and the life lived, and how the relationship between these four instances reveals fragments of the daily lives of traditional populations.
\end{abstract}

Keywords: traditional knowledge; dialogical discourse analysis; ideological sign.

\section{Introdução}

O gênero injuntivo oral, objeto deste trabalho, é aqui tratado como signo ideológico, pois interessa entender como estão materializadas, nas enunciações, as tensões existentes na vida social das populações tradicionais e, por sua vez, apontar a importância de tornar tangível a plurivalência social do signo ideológico presente nesses contextos. Esses gêneros, segundo a literatura especializada, têm uma função social 
marcante na manutenção, reprodução e, também, como traço caracterizador do modo de vida das populações ou comunidades tradicionais.

Outras abordagens pautadas na Linguística investigaram os conhecimentos de populações humanas sobre os processos naturais, como o enfoque dado pela Etnociência, que partiu da linguística, mais precisamente do objetivismo abstrato imanente ao estruturalismo saussuriano, para debruçar-se sobre os etnoconhecimentos, a fim de identificar, classificar e registrar os conhecimentos ancestrais de povos tradicionais.

Apesar das limitações próprias de uma abordagem do sistema, não há como negar que o enfoque linguístico utilizado pelos etnocientistas, quando do reconhecimento da complexidade e da valorização do "pensamento selvagem" (LÉVISTRAUSS, 1989), historicamente, rejeitado pelos paradigmas positivistas, apontou, ainda nos anos 1960, a necessidade de a pesquisa no campo da antropologia dialogar com os estudos linguísticos e se lançar à investigação do principal meio de reprodução e manutenção de um modo de vida, a transmissão oral.

Apesar de reconhecer a contribuição da antropologia estruturalista, consideramos que seus resultados, pautados em um rigor científico que objetiva os fenômenos sociais em categorias estanques, debilitam e degeneram a vida vivida em alegoria, e, por fim, forjam um objeto acabado e sem relevância para a reprodução da vida social.

$\mathrm{Na}$ contramão dos paradigmas positivistas, é possível perceber a importância dada pelo Círculo de Bakhtin, no estudo da prosa romanesca, à manutenção e à autonomia das diferentes vozes sociais - ou línguas sociais. Tanto o conceito de dialogismo quanto as categorias da polifonia - a realidade em formação, inconclusibilidade, não acabamento e dialogismos (BEZERRA, 2014) -, ressalvam a manutenção do fluxo social para a contínua renovação das bases ideológicas embutidas nas práticas cotidianas e, por conseguinte, refletidas e refratadas pelo signo ideológico. Segundo Faraco (2009, p. 62), “As raízes da valorização do cotidiano estão, certamente, no envolvimento filosófico inicial de Bakhtin com o mundo da vida [...] mas, também, no embate do Círculo com a poética formalista".

Ao valorizar a manutenção do fluxo contínuo de vozes, o método sociológico pressupõe o reconhecimento da interdependência entre as duas esferas da criação ideológica citadas acima: a esfera que compreende a totalidade das atividades sociais centradas na vida cotidiana - a ideologia do cotidiano -, e a que compreende a totalidade das práticas socioideológicas culturalmente mais elaboradas - os sistemas ideológicos constituídos.

Ao ponderar sobre o cenário socioideológico e discursivo, imanentes à vida social de sujeitos imersos no modo de vida tradicional, o método sociológico nos permite reunir os fragmentos de uma realidade obliterada pela ideologia dominante e por suas bases filosóficas positivistas. Nesse caso, os gêneros orais usados na transmissão de saberes ancestrais, entendidos como signos ideológicos que refletem e refratam uma dada realidade, permitem, potencialmente, compreender a realidade ideológica da relação entre a infra e a superestrutura, sem, contudo, cair em explicações pautadas em causalidades. 
Antes de mais nada, é impossível estabelecer o sentido de uma dada transformação ideológica no contexto da ideologia correspondente, considerando que toda esfera ideológica se apresenta como um conjunto único e indivisível cujos elementos, sem exceção, reagem a uma transformação da infra-estrutura. Eis por que toda explicação deve ter em conta a diferença quantitativa estre as esferas de influência recíproca e seguir passo a passo todas as etapas da transformação. Apenas sob esta condição a análise desembocará, não na convergência superficial de dois fenômenos fortuitos e situados em planos diferentes, mas num processo de evolução social realmente dialético, que procede da infra-estrutura e vai tomar forma nas superestruturas (BAKHTIN/VOLOSHÍNOV, 2010, p. 40-41).

Nesse sentido, a permanência dos saberes tradicionais ao longo das gerações nos interessa não somente pela sua conservação no tempo, mas pela capacidade de se reproduzir e de atualizar suas técnicas e processos produtivos de baixo impacto ambiental. Ainda, consideramos o reconhecimento de um modo de vida em que as relações interpessoais se mantêm a partir de um sistema "de comunitário"1, pautado em princípios de solidariedade e valorização da relação entre o homem e a natureza, algumas das particularidades que distinguem esse modo de vida do urbano-industrial. Este, em crise desde o final do século XIX, vê-se diante do desafio de enfrentar o aprofundamento do isolamento dos sujeitos sociais e o alto impacto causado ao meio ambiente.

\section{O conhecimento tradicional e o método sociológico bakhtiniano}

De antemão, podemos afirmar que duas motivações de cunho ético e social justificam esta pesquisa. A primeira diz respeito à necessidade de a esfera científica, fazendo uma recapitulação de suas bases epistemológicas, outorgar o conhecimento produzido aquém dos paradigmas ali sobrepujantes e, ainda, manter o cuidado de não tratar o etnoconhecimento como um relicário a ser preservado, isto é, um conhecimento acabado.

A segunda motivação tem sua origem no fato de considerar as transmissões orais de conhecimentos ancestrais o resultado de complexos processos históricos estabelecidos na relação entre a infra e a superestrutura. Tal perspectiva pretende subverter o processo de monovalência do signo descrito por Bakhtin/Voloshínov (2010, p. 48):

Aquilo mesmo que torna o signo ideológico vivo e dinâmico faz dele um instrumento de refração e de deformação do ser. A classe dominante tende a conferir ao signo ideológico um caráter intangível e acima das diferenças de classe, a fim de abafar ou de ocultar a luta dos índices sociais de valor que aí se trava, a fim de tornar o signo monovalente.

\footnotetext{
${ }^{1}$ A inclusão incomum da preposição de antes do nome comunitário - de comunitário - diz respeito à perspectiva presente nos estudos desenvolvidos no campo da ecologia social que define formas de organização social. Nesse sentido, quando falamos de sistemas de comunitários e não sistemas comunitários, o que se está querendo pontuar é um sistema que gira em torno de um tipo específico de organização social.
} 
A monovalência do signo ideológico, no contexto brasileiro, possibilita conferir aos sistemas ideológicos, presentes nas diversas esferas da vida social, o poder de cerceamento dos direitos básicos para algumas populações, estes inerentes ao modelo social republicano. $\mathrm{O}$ insistente silenciamento das populações tradicionais acabou por lhes conferir um espaço mínimo nas diversas esferas da vida social e, consequentemente, um fraco poder político e a marginalização.

Diante deste cenário de tensões inerentes às lutas de classes, acreditamos que o enfoque nos gêneros orais - em função da importância e do reconhecimento conferido a estes gêneros, para o acesso e entendimento dos processos de produção e reprodução da vida social de populações tradicionais - possa trazer, à tona, questões como as abordadas por campos da sociologia que investigam a relação estabelecida entre o homem e o meio ambiente, considerando que é no entendimento desta relação que subjaz a compreensão sobre a reprodução da vida humana, como o EcoSocialismo/Marxismo.

Para entender como se delinearam as pesquisas que mantêm suas abordagens pautadas nos paradigmas propostos pelo Eco-Socialismo/Marxismo, Diegues (2008) afirma que esta abordagem, inicialmente, se ocupou da crítica aos princípios presentes no marxismo clássico, os quais pressupõem uma visão de natureza estática (simples mercadoria) que, à mercê da intervenção humana e das forças produtivas do trabalho, disponibiliza os recursos necessários para a reprodução da vida humana.

Em contrapartida, os ecomarxistas passaram a propor alguns conceitos que faziam uma revisão dos paradigmas do marxismo clássico, entre eles o de forças produtivas da natureza (GUTELMAN, 1974 apud DIEGUES, 2008) em oposição às forças produtivas históricas. Nesse viés crítico, é estabelecida uma relação indissociável entre homem e natureza, como um sistema de interdependência em que ambos se retroalimentam, isto é, "a infraestrutura não é composta somente pelas forças produtivas do trabalho e pelas relações sociais de produção, mas, também, pelas forças produtivas da natureza" (SKIBBERG, 1974 apud DIEGUES, 2008, p. 49), e na inexistência de operação entre essas forças, cria-se um impasse para a reprodução da sociedade.

Diante de tal perspectiva, um entendimento inicial do modo de vida de comunidades pautadas nesta relação, indissociável, estabelecida entre homem e natureza, pressupõe o reconhecimento de seus saberes como resultado de processos históricos e sociais balizados por sistemas ideológicos.

Partindo deste pressuposto, identificamos nos signos ideológicos que compõem os enunciados orais, da entrevista feita com um homem e uma mulher, casados há 24 anos, habitantes de uma agrovila localizada na Vila de Apeú, distante 65,5 km de Belém, capital do Pará, elementos que, além de caracterizar o modo de vida dos sujeitos integrantes de uma comunidade tradicional, também apontam para o lugar que estes sujeitos ocupam tanto nos sistemas reprodutivos, presentes na microestrutura social de sua comunidade, como na macroestrutura socioeconômica brasileira.

A abordagem, aqui empregada, está pautada no método sociológico proposto pelo Círculo de Bakhtin, o qual pressupõe que a relação dialética estabelecida entre a infra e superestrutura espraia-se nas relações sociais que se materializam nos signos 
ideológicos. Dessa maneira, o ponto de partida para a análise do gênero do discurso, o objeto de análise de trabalho, considerará os seguintes procedimentos metodológicos:

1. Não separar a ideologia da realidade material do signo (colocando-a no campo da "consciência" ou em qualquer outra esfera fugidia e indefinível).

2. Não dissociar o signo das formas concretas da comunicação social (entendendo-se que o signo faz parte de um sistema de comunicação social organizada e que não tem existência fora deste sistema, a não ser como objeto físico).

3. Não dissociar a comunicação e suas formas de sua base material (infra-estrutura) (BAKHTIN/ VOLOSHÍNOV, 2010, p. 45).

Por sua vez, Fiorin (2010) lembra que a análise translinguística (ou metalinguística segundo Paulo Bezerra), proposta por Bakhtin e seu Círculo, deve valerse das categorias de análise de outras teorias linguísticas, para, então, ter uma base para assentar tal análise.

Sobre o caráter dialógico de todo discurso, Fiorin (2010, p. 40) ressalva que, ao apontar para esse aspecto como uma propriedade central em todo enunciado, Bakhtin pretendia pontuar que:

[...] todo discurso é constituído a partir de outro discurso, é uma resposta, uma tomada de posição em relação a outro discurso. Isso significa que todo discurso é ocupado, atravessado, habitado pelo discurso do outro e, por isso, ele é constitutivamente heterogêneo. Todo enunciador, para construir seu discurso, leva em conta o discurso do outro, que está, por isso, presente no seu. Assim, um discurso deixa ver seu direito e seu avesso. Neles, estão presentes, pelo menos, duas vozes, a que é afirmada e aquela em oposição à qual se constrói.

Dessa maneira, o grande desafio deste trabalho será identificar, na análise dialógica dos enunciados, a atividade histórica e sociocultural de populações marginalizadas, por paradigmas positivistas, colonialistas e eurocêntricos, sem, contudo, tratá-los como um objeto acabado, mas, ao contrário, um processo, algo inacabado, dando voz a sujeitos situados e emudecidos, historicamente, pela ideologia dominante. Assim, conferimos um lugar de destaque para a reprodução da vida humana na região Amazônica.

\section{A reprodução da vida em uma comunidade rural amazônica}

A entrevista, recurso metodológico para a produção de material desta análise, ocorreu no dia 17 de março de 2016, em uma comunidade rural, situada a 65,5 km de Belém, capital do estado do Pará. A referida comunidade está localizada na vila distrital de Apeú, no município de Castanhal $^{2}$, e tem uma população em torno de 12 mil habitantes (BRASIL, 2016).

\footnotetext{
${ }^{2}$ Segundo as estimativas populacionais do IBGE para o senso de 2016, o município de Castanhal conta com uma população em torno de 192.571 habitantes e uma área total de $1.028 .889 \mathrm{~km}^{2}$ (BRASIL, 2016).
} 
Tanto a vila distrital de Apeú quanto o município de Castanhal têm como marco histórico instituído de seu surgimento o projeto de construção da ferrovia BelémBragança, estrada que ligou Belém ao município de Bragança e fazia o escoamento da produção agrícola e da borracha extraída na mesorregião nordeste do Pará. Durante a sua construção, iniciada em 1803 e finalizada em 1908, a estrada de ferro chegou a 222 km de extensão e 1 metro de bitola; para isso, foi necessário um enorme contingente de mão de obra que não havia na região. A grande maioria dos trabalhadores foi de imigrantes nordestinos, os quais se juntaram aos colonos e, hoje, formam a população da referida mesorregião.

Segundo Diegues (2008, p. 89-90), é possível identificar alguns critérios que caracterizam as culturas e sociedades tradicionais, a saber:

a) Dependência e até simbiose com a natureza, os ciclos naturais e os recursos naturais renováveis a partir dos quais se constrói um modo de vida;

b) Conhecimento aprofundado da natureza e de seus ciclos que se reflete na elaboração de estratégias de uso e de manejo dos recursos naturais. Esse conhecimento é transferido de geração em geração pela oralidade;

c) Noção de território ou espaço onde o grupo social se reproduz econômica e socialmente;

d) Moradia e ocupação do território por várias gerações, ainda que alguns membros individuais possam ter-se deslocado para os centros urbanos e voltado para a terra de seus antepassados;

e) Importância das atividades de subsistência, ainda que a produção de mercadorias possa estar, mais ou menos, desenvolvida, o que implica uma relação com o mercado;

f) Reduzida acumulação de capital;

g) Importância dada à unidade familiar, doméstica ou comunal e às relações de parentesco ou compadrio para o exercício das atividades econômicas, sociais e culturais;

h) Importância das simbologias, mitos e rituais associados à caça, à pesca e atividades extrativistas;

i) A tecnologia utilizada é relativamente simples, de impacto limitado sobre o meio ambiente. Há reduzida divisão técnica social do trabalho, sobressaindo o artesanal, cujo produtor (e sua família) domina o processo de trabalho até o produto final;

j) Fraco poder político, que, em geral, reside com os grupos de poder dos centros urbanos;

k) Auto-identificação ou identificação pelos outros de pertencer a uma cultura distinta das outras. 
Por sua vez, além das características mencionadas acima, outro fator, ainda, precisa ser considerado. Nas populações tradicionais, as quais estão incluídas as indígenas e as não indígenas (camponesas), que apesar de seus modelos de reprodução social estarem muito próximos, diferenciam-se pela estreita relação que a cultura camponesa mantém com outra cultura (nacional, urbano-industrial). Para Diegues (2008), é com base neste elemento que tem se estabelecido o conceito de etnia às populações indígenas, pois os povos indígenas, diferentemente dos camponeses, têm culturas claramente diferenciadas das demais, o que nos impele a ressalvar que os interlocutores de nossa pesquisa são sujeitos imersos em outras culturas e, por isso, compõem as populações tradicionais definidas como camponesas.

\section{Os ciclos migratórios e seus reflexos no modo de vida camponês}

A entrevista teve a mediação de um colega pesquisador, que já trabalhou em projetos pela ONU em áreas indígenas, e que mantém um sítio na vila de Apeú. Tão logo soube da pesquisa que iríamos iniciar, este colega identificou na comunidade e em seus vizinhos o perfil que procurava para obtenção do corpus que buscávamos. Não tardou para que o encontro fosse arranjado e, passadas três semanas de nossa conversa, lá estávamos frente a frente ao casal de agricultores, casados há 24 anos, com três filhos, ele com 50 (informante 2) e ela com 42 anos de idade (informante 1), ambos analfabetos e moradores da localidade há 18 anos.

Sem conhecê-los previamente, já que aquele era nosso primeiro encontro, um fato me chamou a atenção: a variante utilizada por ambos não era a mesma usada pelos falantes da região metropolitana de Belém, capital do Pará. Ao interpelá-los sobre sua naturalidade, a resposta que obtive foi que moravam no Cristo Reis, um bairro agrícola localizado na zona urbana do município de Castanhal e, ainda, que seus antepassados, também, eram da localidade. Mas qual a origem daquela variante diatópica? A resposta a esta questão só foi possível após uma investigação sobre o processo de colonização daquela região, quando foi identificada que aquela variante teria potencialmente sua ancestralidade nos imigrantes nordestinos, os quais à época da construção da estrada de ferro vieram em busca de trabalho e, concluída a obra, acabaram permanecendo na região.

Para além desta constatação, pautada em documentos e registro disponíveis na internet, durante a entrevista um fato chamou a atenção neste núcleo familiar. Em diversos momentos, os interlocutores apontam para um processo migratório ininterrupto: do campo para a cidade e vice e versa (01).

(01) Inf. 2. não mais de dizoito, dezoito nós mora aqui.

Doc. ah tá então vocês moravam on/antes

Inf 1 . nós morava lá pru Cristo Reis

A preferência pelo emprego do pretérito imperfeito "morava" aponta a necessidade de o interlocutor indicar um processo inconcluso, o qual, nesse contexto discursivo, encaminha ao entendimento de que a migração é uma condição comum na reprodução da vida social desses sujeitos. 
No exemplo (02), na geração de seus pais, o processo migratório se deu do campo para a cidade.

(02) Inf.1 os meus pai mora lá pru Cristu Reis

Doc. i elis são daqui?

Inf.1 é dali da Iracema é...

Doc. da região

Inf.1 é dali da Iracema mermu da agrovila Iracema

Doc. ah da Agrovila Iracema e a sua avó era daqui?

Inf.1 era

Doc. que é a mãe da tua mãe?

Inf.1 uhum

Doc. então tua a mãe veio/foi daqui pra lá?

Inf. 1 foi casou e foi pra lá

Doc. ah então a origem de vocês é aqui mesmu né?! e tu Zé?

Inf.2 eu também daqui também

Quanto aos interlocutores da entrevista, houve o contrafluxo do êxodo rural, um retorno ao campo, às terras herdadas de uma avó que ali morava até seu falecimento. Uma característica marcante de populações tradicionais é a ocupação do território por várias gerações, mesmo que esta ocupação ocorra por membros que retornam da cidade ao campo (DIEGUES, 2008).

(3) Doc. aí tá e quando vocês vieram pra cá vocês/e como foi que vocês chegaram até aqui?

Inf.2 é porque era da família da...

Inf.1 é de herança isso aqui.

Doc. ah tá então os teus pais já moravam aqui?

Inf.2 não...

Info. 1 era daaa minh/ avó [responde em tom de insegurança] da minha avó mermo né?!

Doc. da tua avó?!

Inf.1. era

Doc. e ela já trabalhava com plantação? como é que ela...

Inf.1 eu acho que sim, mas quantu eu vim prá cá ela já tin/falecidu.

Doc. já tinha falecidu?!

Inf.1 ãhamm

Apesar desta ligação ancestral com a terra, um fato chamou a atenção no enunciado: "Eu acho que sim, mas quantu eu vim prá cá ela já tin/falecidu", o conhecimento sobre os ciclos da natureza e dos processos de produção do modo de vida, que, por ventura, a interlocutora adotava nas terras deixadas pela avó, não fora adquirido por meio direto desta ancestralidade, mas como veremos mais adiante, foram repassados por seus pais.

\section{O modo de vida marcado pela relação simbiótica com os ciclos da natureza}

Por sua vez, o retorno ao campo, além de garantir a reprodução da vida social no modo de vida de seus antepassados, também proporcionou aos interlocutores da pesquisa a autonomia tanto dos meios de produção (a terra e as ferramentas de produção os pertence), quanto no aprofundamento de seus conhecimentos sobre a natureza e seus ciclos, os quais têm se refletido na crescente diversificação de sua produção e na 
contínua experimentação no plantio de novas espécies, o que, além de garantir o manejo ambiental, fomenta estratégias de subsistência.

(4) Doc. aí vocês vieram pra cá e começaram a plantar o quê?

Inf.1 nós prantemu melancia prantava fejão, milhu, roça

Doc. ah tá mas antes de vir pra cá vocês já trabalhavam cum cum plantação?

Inf.1 uhummm

Inf.2 (inaudível) pra São Domingos do Capim

$[\ldots]$

Doc. já raspa/tá mas por exemplo aqui a casa de farinha é de vocês né?!

Inf.1 é!

Doc. $\quad$ é só de vocês daqui da casa de vocês?!

Inf.1 é

Doc. lá quandu tu moravas cum a tua mãe a casa de farinha era da tua família ou era da comunidade?

Inf.1 era tudu dus pessoal assim qui pagava a genti pra genti raspa pra elis e fazê a farinha.

Doc. ah tá então era uma era tipo é privadu assim, era de alguém...

Inf.1 é...

Doc. que pagava vocês pra produzi a farinha?!

Inf.1 uhum::

Doc. ah tá agora essa casa de farinha daqui só vocês que usam?

Inf.1 é só nós

Doc. ah tá não...

Inf.1 num tem outras pessoa só nós mermu

Doc. outras pessoas outras pessoas da comunidade...

Inf.1 não

As comunidades tradicionais criam sistemas de manejo que devem obedecer aos ciclos da natureza, como na região norte só há duas estações - uma que chove mais e outra que chove menos, mas sem grandes períodos de estiagens - é comum o atraso da colheita da mandioca usada na produção da farinha ${ }^{3}$.

(5) Doc. ah tá então basicamente qui vocês vivem hoje em dia mesmu da plantação né?!

Inf.1 a prantação tem tempus qui a roça é um anu né tem qui espera um anu pranta e tem qui espera um anu

Doc. hum::

Inf.1 a roça

Doc. e aí nessi um anu tem qui/ai vocês vão e plantam outras coisas?

Inf.1 é só a roça mermu a roça é um anu né aí quandu é tempu/im anu im anu é essi milhu qui pranta também só im anu im anu

Doc. ah tu tem também tua plantação de milhu?

Inf.1 é:!

Doc. ah entendi mas é o mesmu períudu por exemplu o milhu eli fica bom nu mesmu períudu da farinha da da mandioca?

Inf.1. não mais rápidu

Inf.2 três meis

Inf.1 foi em janeru qui nós prantemu tá saindu agora saiu

\footnotetext{
${ }^{3} \mathrm{O}$ local de plantio da mandioca é denominado de "roça" pela população da região.
} 
Esse conhecimento permite a eles, além de prever o atraso da colheita em função da quantidade de chuvas, saber que período do ano é mais adequado para o plantio deste ou daquele produto e, assim, criar um sistema de controle de sua safra, visando à manutenção do seu modo de vida e de sua sobrevivência.

\section{Como produzir a farinha sem a mandioca: percalços no registro do gênero oral injuntivo}

Sobre o processo de produção de farinha de mandioca, uma das motivações dessa entrevista, interessava registrar a transmissão oral dos saberes ancestrais pois a farinha, assim como o açaí, são produtos da culinária paraense que marcam a forte ligação existente com a cultura das populações indígenas originárias da região e, ainda, com as comunidades caboclas tradicionais amazônicas resultantes da miscigenação daquelas com negros escravos e com os colonos europeus.

No entanto, a obtenção do gênero oral manteve-se limitada pelos conflitos causados pela formalidade da entrevista que criou uma situação artificial de interlocução, e, ainda, pelas distâncias culturais existentes entre o documentador e seus interlocutores.

Porém, esse cenário de tensões tornou-se revelador, pois como a explicação sobre o processo de produção da farinha se deu de maneira inusitada, pois se esperava uma narrativa oral mais longa composta pelas descrições de todo o processo de produção da farinha, tais como: o manuseio da mandioca considerando seus ciclos de produção, as técnicas utilizadas em sua colheita, as etapas de produção e os instrumentos usados em seu manuseio, a produção final até o escoamento, etc., porém, nada disso foi obtido sem que fossem necessárias estratégias argumentativas que promovessem as réplicas requeridas. Em nosso entendimento, os registros abaixo (06 e 07) nos revelaram muito sobre o processo dialógico da enunciação no constante à dinâmica de interação das vozes sociais.

(06) Doc. ah tá e a farinha?

Inf1. a farinha a gente bota de moio

Doc. $\operatorname{sim}$

Inf.1 aí raspa aí rala lá nu motô...

Doc. $\operatorname{sim}$

Inf.1 aí bota na prensa aí seca né o cutupí é aí depois penera aí depois vai escaldá e fica mexendo lá a farinha

(07) Doc. ah antes...depois tu vais mostrar como é que tu fazes?! ((um breve silêncio)) é porque tu me explicastes é aí daqui a pouco tu vais me mostrar como é que faz... ((risos)) mais ou menos...e como foi que tu aprendeste? me fala um pouquinho de COMO TU APRENDESTE a fazê a farinha

Inf.1 é e/aí NÃO eu aprendi assim mermu qui o pa/ o meu pai fazia né e aí a gente vai venu e aí vai fazenu

Doc. aham e aí foi pegandu a mandioca...

Inf.1 ãham aí raspa lava bota no motô fervi aí dá dá/du fervá vai pra prensa da prensa quando tá inxutu penera i vai pru fornu 
Estão em destaque nos exemplos acima (06 e 07) dois momentos de réplica em torno do tópico "processo de produção da farinha". No primeiro, não houve qualquer preparação para introdução do tópico discursivo, pois, até então, não havia um contexto capaz de proporcionar estratégias discursivas para fomento de um evento social, isto é, um repertório cultural presente em esferas ideológicas familiares aos interlocutores. A objetividade das explicações pontuou marcadamente este distanciamento social e apontou para um problema metodológico da pesquisa de campo que precisará ser revisto: a virtualização de uma situação social não negociável em função do distanciamento, que, muito além de estratégias linguísticas, incide em respostas sem réplicas, isto é, não há engajamento ou o engajamento se dá de maneira superficial e, por sua vez, a responsividade fica restrita às réplicas frias, isto é, respostas breves às questões.

Para haver relações dialógicas, é preciso que qualquer material linguístico (ou de qualquer outra materialidade semiótica) tenha entrado na esfera do discurso, tenha sido transformado num enunciado, tenha fixado a posição de um sujeito social. Só assim é possível responder (em sentido amplo e não apenas empírico do termo), isto é, fazer réplicas ao dito, confrontar posições, dar acolhida fervorosa à palavra do outro, confirmá-la ou rejeitá-la, buscar-lhe um sentido profundo, ampliá-la. Em suma, estabelecer com a palavra de outrem relações de sentido de determinada espécie, isto é, relações que geram significação responsivamente a partir do encontro de posições avaliativas. (FARACO, 2009, p. 66, grifo do autor).

Apesar do insucesso na empreitada a que havíamos nos lançado, há de se considerar algumas extrapolações: apesar de não conseguir o engajamento necessário para obter o gênero oral que configurasse o que esperávamos de uma transmissão oral de conhecimentos tradicionais, as respostas dadas pela interlocutora correspondem composicionalmente ao gênero injuntivo, pois ao pontuar as etapas de produção da farinha, com verbos no imperativo, utiliza, neste caso, o marcador discursivo aí como elemento de progressão discursiva e temporal à enunciação e, desta maneira, enuncia do lugar conferido a ela como detentora daquele conhecimento que conhece profundamente aquele processo.

\section{Cada um ocupa seu lugar no sistema de reprodução do modo de vida tradicional}

Um último aspecto que merece destaque diz respeito aos lugares que cada sujeito ocupa nas diversas esferas da vida em sociedade, e que no modo de vida tradicional obedece às condições de reprodução da vida social ali presentes.

(08) Doc. ah tá mas mi diz uma coisa como foi que vocês aprenderam? como foi que tu aprendeste a fazê farinha?

Inf. 1 foi cum meus pai mermu

Doc. Ah:: então tua família já trabalhava...

Inf.1 Aham::

Doc. cum a farinha? E tu começaste a trabalha com a farinha muito jovem? com quantos anus mais ou menos?

Inf.1 é achu que um ti/uns dez anu a minha mãe já rapava mandioca prus otro 
(09) Doc. me fala um pouquinho de COMO TU APRENDESTE a fazê a farinha.

Inf.1 é e/aí NÃO eu aprendi assim mermu qui o pa/ o meu pai fazia né e aí a gente vai venu e aí vai fazenu.

(10) Doc. ah tá e cum quantus anus tu começaste a fazê todu essi processu? porque logu nu início tu só raspava.

Inf.1 era... já depois que eu vim morá prá cá eu mermu torru

Doc. ah tá que tu viesti fazer todu u processu.

Inf.1 ãham::

Doc. já depois qui tu tava casada com o Zé.

Inf.1 ãham:::

Inf.2 é

De acordo com as réplicas, o aprendizado das técnicas de produção naquele modo de vida tradicional se deu por meio do compartilhamento das atividades entre adultos, jovens e crianças. A interlocutora pontuou que não houve um momento específico para tal aprendizado o qual envolvesse o próprio processo de produção, tanto que, quando interpelada pela segunda vez sobre como teria aprendido a fazer farinha, a interlocutora hesita para se engajar na réplica. Quando se engaja, usa, nesta e nas outras duas réplicas, a mesma pergunta, o advérbio "mermu" muito utilizado na linguagem oral para incorporar o sentido de um processo que se dá naturalmente, o que leva a crer que se trata de uma espécie de convenção daquele modo de vida.

Tal dinâmica de aprendizagem remete a uma ancestralidade indígena, em que o modo de transmissão de saberes se dá por meio da integração desde a infância às atividades de subsistência, as crianças são incluídas nas tarefas, participando de todas as etapas e respeitando o grau de complexidade à faixa etária.

No caso desta comunidade, as etapas de aprendizado, também, consideram o lugar e as tarefas destinadas a cada sujeito em função do gênero e de sua faixa etária. Para as mulheres e crianças, no processo de produção de farinha estritamente mercantil é conferida a função de ralar a mandioca, o que seria a etapa inicial e que requer um grau de esforço mediano, quando consideramos que todas as etapas se dão por meio de um processo estritamente artesanal. Quando a produção passa para uma esfera familiar, os papéis se sobrepõem, e as mulheres adultas passam a participar do início ao fim do processo de produção.

\section{Algumas considerações finais}

Constatou-se que, mantida a indissociabilidade entre sujeito e contexto, a interpretação discursiva de gêneros orais injuntivos produzidos por interlocutores imersos no modo de vida tradicional aponta para singularidades somente identificáveis em situações de proximidade entre o homem e o meio ambiente: técnicas produtivas simples e artesanais, com baixo impacto ambiental; a manutenção de relações interpessoais organizadas em um modelo de comunal mantidas por laços familiares ou de compadrio; profundo conhecimento dos ciclos da natureza; permanente experimentação de técnicas de cultivo e manejo sustentável da floresta, etc.

A entrevista composta de réplicas breves permitiu identificar fragmentos da vida social dessas populações e compreender como: (a) os ciclos migratórios podem ser 
processos comuns a este modo de vida, (b) o aprofundamento do conhecimento sobre os ciclos da natureza são fundamentais para a reprodução daquele modo de vida, ou ainda (c) cada sujeito desempenha funções no processo de produção, as quais se alternam de acordo com o sistema de produção: mercantil ou de subsistência.

Desta maneira, diante da observação sobre a dinâmica de produção e reprodução de técnicas e saberes, a crença do "senso comum, [de que] o conhecimento tradicional é um tesouro no sentido literal da palavra, um conjunto acabado que se deve preservar, um acervo fechado transmitido por antepassados e a que não vem ao caso acrescentar nada" (CUNHA, 2007, p. 78) é imediatamente refutada, e vale associar tal crença a alguns pré-conceitos emergentes da ciência positivista. De acordo com Bakhtin/Voloshínov (2010), o senso comum está contido na ideologia do cotidiano, esfera que mantém uma indissociável interdependência com os sistemas ideológicos constituídos (arte, ciência, direito, moral etc.).

Diante de tais constatações, seria uma tolice acreditar que estariam referenciados aqui todos os fragmentos da vida constantes nos signos ideológicos que comportam o corpus analisado, ou que tal análise pretendia-se exaustiva. Contudo, citamos ainda um último fenômeno, o qual não teve espaço ao longo do texto, mas que também aponta indícios de um modo de vida: ao longo da interlocução, há o uso recorrente da expressão a gente, em substituição ao pronome pessoal de primeira pessoa do plural nós, o qual não foi aqui analisado, mas que sabemos que discursivamente o uso desta expressão em substituição ao pronome confere uma amplitude ao referente, um tom de impessoalidade à enunciação. No contexto da entrevista, essa amplitude é sempre utilizada quando os interlocutores se reportam às atividades produtivas ou aos conhecimentos ancestrais. As reflexões que compõem este trabalho proporcionaram alcançar os fragmentos de uma realidade que vem sendo negligenciada e, em algumas esferas ideológicas, apagada.

\section{REFERÊNCIAS}

BAKHTIN, M. M. [1895-1975]. Estética da criação verbal. Tradução de Paulo Bezerra. 6. ed. São Paulo: Editora WMF Martins Fontes, 2011.

BAKHTIN, M. M.; VOLOSHÍNOV, V. N. Marxismo e filosofia da linguagem: problemas fundamentais do método sociológico da linguagem. 14. ed. São Paulo: Hucitec, 2010.

BEZERRA, P. Polifonia. In: BRAIT, B. (Org.). Bakhtin: conceitos-chave. 5. ed. 2. reimp. São Paulo: Contexto, 2014. p. 191-200.

CUNHA, M. C. Relações e dissensões entre saberes tradicionais e saber científico. Revista USP, São Paulo, n. 75, p. 76-84, set./nov. 2007.

DIEGUES, A. C. O mito moderno da natureza intocada. 6. ed. São Paulo: Ed. Hucitec, NUPAUB, 2008.

FARACO, C. A. Linguagem e diálogo: as idéias linguísticas do círculo de Bakhtin. São Paulo: Parábola Editorial, 2009. 
FIORIN, J. L. Categorias de análise em Bakhtin. In: DE PAULA, L.; STAFUZZA, G. (Org.). Círculo de Bakhtin: diálogos in possíveis. Campinas: Mercado das Letras, 2010. (Série Bakhtin: Inclassificáveis; v. 2). p. 33-48.

BRASIL. IBGE: Cidades. Disponível em: $<$ https://cidades.ibge.gov.br/v4/brasil/pa/castanhal/panorama $>$. Acesso em: 07 mai. 2016.

LÉVI-STRAUSS, C. O pensamento selvagem. Tradução de Tânia Pellegrini. 8. ed. Campinas: Papirus, 1989.

Recebido em: 01/09/2016

Aprovado em: 29/11/2016 